\title{
Long-term decline in lung function, utilisation of care and quality of life in modified GOLD stage 1 COPD
}

\author{
P-0 Bridevaux, ${ }^{1}$ M W Gerbase, ${ }^{1}$ N M Probst-Hensch, ${ }^{2}$ C Schindler, ${ }^{3}$ J-M Gaspoz, ${ }^{4}$ \\ T Rochat ${ }^{1}$
}

\section{See Editorial, p 756}

- Further information is published online only at http:// thorax.bmj.com/content/vol63/ issue 9

${ }^{1}$ Division of Pulmonary Medicine, Geneva University Hospitals and University of Geneva, Switzerland;

${ }^{2}$ Molecular Epidemiology/Cancer Registry, Institutes of Social and Preventive Medicine and Surgical Pathology, University of Zurich, Switzerland; ${ }^{3}$ Institute of Social and Preventive Medicine, University of Basle, Switzerland;

${ }^{4}$ Division of Community

Medicine and Primary Care, University Hospitals of Geneva University of Geneva Medical School, Switzerland

Correspondence to: Dr P-0 Bridevaux, University Hospitals of Geneva, Division of Pulmonary Medicine, 24 rue

Micheli-du-Crest, 1211 Geneva, Switzerland;

Pierre-Olivier.Bridevaux@hcuge.ch

Received 3 December 2007 Accepted 8 April 2008 Published Online First 27 May 2008

\begin{abstract}
Background: Little is known about the long-term outcomes of individuals with mild chronic obstructive pulmonary disease (COPD) as defined by the Global Initiative for Chronic Obstructive Lung Disease (GOLD).

Methods: A population cohort of 6671 randomly selected adults without asthma was stratified into categories of modified GOLD-defined COPD (prebronchodilator spirometry). Further stratification was based on the presence or absence of respiratory symptoms. After 11 years, associations between baseline categories of COPD and decline in forced expiratory volume in $1 \mathrm{~s}\left(\mathrm{FEV}_{1}\right)$, respiratory care utilisation and quality of life as measured by the SF-36 questionnaire were examined after controlling for age, sex, smoking and educational status. Results: At baseline, modified GOLD criteria were met by $610(9.1 \%)$ participants, $519(85.1 \%)$ of whom had stage 1 COPD. At follow-up, individuals with symptomatic stage 1 COPD $(\mathrm{n}=224)$ had a faster decline in $\mathrm{FEV}_{1}(-9 \mathrm{ml} /$ year $(95 \% \mathrm{Cl}-13$ to -5$))$, increased respiratory care utilisation (OR $1.6(95 \% \mathrm{Cl} 1.0$ to 2.6)) and a lower quality of life than asymptomatic subjects with normal lung function ( $n=3627$, reference group). In contrast, individuals with asymptomatic stage 1 COPD $(n=295)$ had no significant differences in $\mathrm{FEV}_{1}$ decline $(-3 \mathrm{ml} /$ year $(95 \% \mathrm{Cl}-7$ to +1$))$, respiratory care utilisation (OR 1.05 $(95 \% \mathrm{Cl} 0.63$ to 1.73$))$ or quality of life scores compared with the reference group.
\end{abstract}

Conclusions: In population-based studies, respiratory symptoms are of major importance for predicting longterm clinical outcomes in subjects with COPD with mild obstruction. Population studies based on spirometry only may misestimate the prevalence of clinically relevant COPD.

The Global Initiative for Chronic Obstructive Lung Disease (GOLD), updated in 2006, distinguishes four categories of severity of chronic obstructive lung disease (COPD) based on a fixed ratio of forced expiratory volume in $1 \mathrm{~s}\left(\mathrm{FEV}_{1}\right) /$ forced vital capacity (FVC) and the percentage predicted $\mathrm{FEV}_{1}$ value. ${ }^{1}$ This classification has been issued to help clinicians detect COPD and offer up-to-date treatment to patients; it has been proposed as a research tool for international comparisons of the prevalence of COPD as well as a common definition in clinical trials. The GOLD classification has also been promoted to estimate future healthcare resources as a result of the growing prevalence of the disease.

Many population studies on the prevalence of COPD rely on airflow obstruction as measured by spirometry without requirement for reporting symptom, exposure to noxious particles or fumes. ${ }^{2-9}$ During the period 1990-2004, Halbert et al found a pooled prevalence of spirometry-defined COPD of $9.2 \%$ whereas the prevalence of physician-diagnosed or self-reported COPD was lower. ${ }^{10}$ More recently the Burden Of Obstructive Lung Disease (BOLD) initiative reported a prevalence of GOLD stage 1 COPD varying between 1.4\% (Philippines) and $15.5 \%$ (Austria). ${ }^{8}$ Also, in population studies, GOLD stage 1 COPD is frequently the most prevalent stage of the disease. For example, in five Latin American cities the prevalence of GOLD stage 1 COPD ranged from $5.2 \%$ to $12.5 \%$ whereas stage 2 or higher was uniformly lower (2.6-7.1\%). ${ }^{9}$

The impact on mortality, healthcare utilisation and quality of life of subjects with GOLD stages 2 4 COPD - which include subjects with abnormal $\mathrm{FEV}_{1} / \mathrm{FVC}$ ratio and $\mathrm{FEV}_{1}$ below $80 \%, 50 \%$ and $30 \%$ respectively-is well recognised. ${ }^{11}{ }^{12}$ In contrast, the clinical significance of GOLD stage 1 COPD which encompasses subjects with $\mathrm{FEV}_{1} /$ $\mathrm{FVC}<70 \%$ and $\mathrm{FEV}_{1} \geqslant 80 \%$ predicted is much less clear.

Two population-based studies have specifically addressed the question of mortality in COPD according to the GOLD classification. ${ }^{13} 14$ Both showed that GOLD stage 1 COPD was associated with a slightly increased mortality, but only when these subjects had symptoms of chronic bronchitis. Data on the association between GOLD stage 1 COPD and healthcare utilisation are scarce. The net risk for COPD-related hospitalisation was increased in subjects with GOLD stage 1 COPD in one report. However, these data suggested that the risk was not higher than in chronic bronchitis without obstruction. ${ }^{15}$

Since subjects with mild GOLD stage 1 COPD generally constitute more than half the individuals with COPD in population studies, it is crucial to have more information about them on clinically relevant outcomes. This could help provide accurate estimates of healthcare need and risk prediction for individuals with mild, GOLD-defined abnormal lung function.

The aim of this study was to compare the longterm decline in $\mathrm{FEV}_{1}$, respiratory care utilisation and quality of life between individuals with symptomatic and asymptomatic stage $1 \mathrm{COPD}$.

\section{METHODS}

\section{Study population}

The SAPALDIA cohort (Swiss Study on Air Pollution and Lung Diseases in Adults) $(n=9651)$, a random sample of the Swiss population, was initially assembled in 1991 to address the effect of air pollution on respiratory health. 
Figure 1 Flow chart of participants included in the present study (SAPALDIA, 1991-2002). PFTs, pulmonary function tests; SF-36, Medical Outcomes Study 36-item Short-Form General Health Survey.

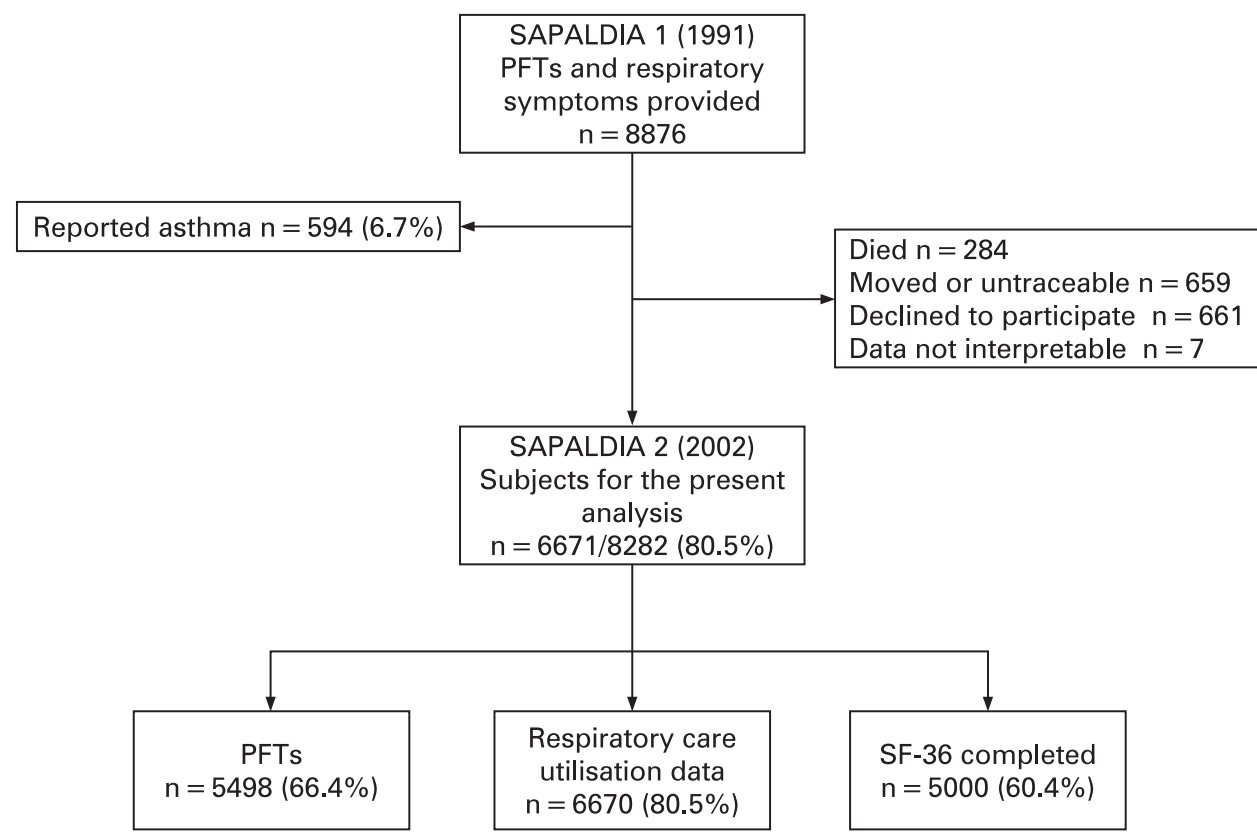

Detailed descriptions of the SAPALDIA study are published elsewhere. ${ }^{16} 17$ Briefly, individuals aged 18-60 years were randomly drawn from local registries of eight areas chosen to represent cultural and geographical diversity of Switzerland (Geneva, Basel, Lugano, Aarau, Wald, Payerne, Davos and Montana). Of these, 8876 had interpretable spirometry and provided information about respiratory symptoms in 1991. For this study, subjects who reported physician-diagnosed asthma at SAPALDIA 1 (1991) were excluded ( $n=594$, fig 1). Of the 8282 eligible subjects from the 1991 sample, the follow-up study in 2002 included 6671 subjects (participation rate $80.5 \%$ ). In the present analysis, 5498 (66.4\%) underwent pulmonary function tests, 6670 (80.5\%) reported healthcare utilisation and 5000 (60.4\%) filled in the Short-Form 36 questionnaire (SF-36). Ethics committee approval was obtained from the participating centres and from the Swiss Academy of Medical Science.

\section{Pulmonary function tests and symptoms assessment}

Pulmonary function tests were performed according to the American Thoracic Society Standards in 1991 and 2002 using the same spirometers (SensorMedics 2200 SP, Yorba Linda, CA, USA). The longitudinal validity of the spirometers was also verified. ${ }^{18}$ The forced expiratory manoeuvre was obtained without bronchodilators. The predicted values for $\mathrm{FEV}_{1}$ and FVC were calculated using the 1993 European Respiratory Society equation. ${ }^{19}$ The modified GOLD classification was adapted to group subjects with $\mathrm{FEV}_{1} / \mathrm{FVC}<0.7$ and prebronchodilator $\mathrm{FEV}_{1} \geqslant 80 \%$ into the stage $1 \mathrm{COPD}$ category and those with $\mathrm{FEV}_{1}<80 \%$ into a single stage $2-4$ category. Respiratory symptoms were considered present if subjects reported chronic cough, phlegm or shortness of breath while walking at the baseline examination (1991). Respiratory questionnaires are shown in the online supplement. Finally, the cohort $(n=6671)$ was stratified on the basis of the GOLD classification and the presence/absence of respiratory symptoms at the first examination (SAPALDIA 1, 1991).

The annual decline in $\mathrm{FEV}_{1}$ was calculated by subtracting the first from the second $\mathrm{FEV}_{1}$ absolute value, divided by the time between the two measurements.

\section{Respiratory care utilisation}

Any report to the interviewer of inhaler use, emergency room visit or hospitalisation due to respiratory problems, ambulatory visit to a chest physician, to an asthma specialist or to a primary care provider for respiratory problems during the year preceding the follow-up survey (SAPALDIA 2, 2002) was considered as "respiratory care utilisation".

\section{Quality of life}

The Medical Outcomes Study 36-item Short-Form General Health Survey (SF-36) was filled in at the follow-up examination in 2002. As Switzerland is a multilingual country, German, French or Italian versions were administered..$^{20-22}$ The Physical Component Summary (PCS) and the Mental Component Summary (MCS) were derived from the questionnaires. ${ }^{23}$

\section{Covariates}

Nationality, education level, smoking status (never, former, current) and lifetime smoking (packs/year) were derived from the main health inventory questionnaires. Height, weight and body mass index (BMI) were recorded immediately before pulmonary function testing. ${ }^{17}$

\section{Statistical analysis}

Outcomes of interest were mean $\mathrm{FEV}_{1}$ decline per year, respiratory care utilisation and SF-36 summary scores. Main predictors of interest were the modified GOLD categories stratified by the presence or absence of respiratory symptoms. We developed mixed linear and logistic regression models with adjustment for age, sex, baseline $\mathrm{FEV}_{1}$, smoking status, lifetime smoking, baseline BMI $\left(\mathrm{kg} / \mathrm{m}^{2}\right)$, weight change, education level, nationality and study area (random effect).

To address the issue of missing responses, we fitted a logistic regression model to predict the probability of non-participation using baseline variables. As a sensitivity analysis, regression models were rerun while weighting each observation by the inverse of the respective subject's propensity of participation. Additional analyses were performed without excluding those with physician-diagnosed asthma in 1991. The association 
between the specific outcome "emergency room visits or hospitalisation due to respiratory problems" and modified GOLD and symptom categories was also examined. Finally, the effect of smoking persistence or cessation between the two surveys was assessed.

All analyses were conducted with Stata 10.0 Version (StataCorp, Texas, USA).

\section{RESULTS}

\section{Characteristics of the SAPALDIA cohort and of participants}

Table A in the online supplement shows the characteristics of the cohort at SAPALDIA 1 (1991). Overall, 610 subjects $(9.1 \%)$ had an $\mathrm{FEV}_{1} / \mathrm{FVC}$ ratio $<0.7$ and were classified as having COPD according to the prebronchodilator GOLD-defined fixed ratio. Of these, 519 (85.1\%) had an $\mathrm{FEV}_{1} \geqslant 80 \%$ of the predicted value and were classified as stage $1 \mathrm{COPD}$. More than half the subjects classified as stage 1 COPD were free of respiratory symptoms ( $\mathrm{n}=295 ; 56.8 \%$ ). Overall, individuals with modified GOLD-defined obstruction were older, more frequently male and ever-smokers.

Compared with participants, non-participants at SAPALDIA 2 were more likely to be younger, non-Swiss citizens, current smokers, obese and to have respiratory symptoms at SAPALDIA 1. More information on non-participants is given in tables $B$ and $\mathrm{C}$ in the online supplement.

\section{Decline in FEV}

The mean (SD) annual decline in $\mathrm{FEV}_{1}$ over 11 years was 35 (29) $\mathrm{ml} /$ year for subjects with normal lung function $(\mathrm{n}=4997)$, 40 (37) $\mathrm{ml} /$ year for those with stage $1 \mathrm{COPD}(\mathrm{n}=430)$ and $28(40) \mathrm{ml} /$ year for those with stage 2-4 COPD $(\mathrm{n}=71)$ $(p<0.01)$. Table 1 summarises the unadjusted decline in $\mathrm{FEV}_{1}$ by modified GOLD stage and by symptom categories. Compared with asymptomatic subjects with normal lung function (reference group), the unadjusted decline in $\mathrm{FEV}_{1}$ was faster only for symptomatic subjects with normal lung function $(p=0.001)$ and for symptomatic subjects with stage 1 COPD $(p<0.001)$. Within stage 1 COPD, a trend towards a faster decline in $\mathrm{FEV}_{1}$ was seen before adjustment for symptomatic (mean (SD) $-44(38) \mathrm{ml}$ ) versus asymptomatic subjects (mean $(\mathrm{SD})-38(36) \mathrm{ml})(\mathrm{p}=0.11)$.

Figure 2 shows the results of the multivariate analysis of mean annual decline in $\mathrm{FEV}_{1}$ over 11 years by modified GOLD categories and stratified by the presence of symptoms at SAPALDIA 1 (1991). The presence of symptoms in subjects with normal lung function at baseline was associated with a significant difference in the decline in $\mathrm{FEV}_{1}$ compared with the reference group ( $-4 \mathrm{ml} /$ year $(95 \% \mathrm{CI}-5$ to -2$)$ ). Likewise, subjects with symptomatic stage $1 \mathrm{COPD}$ had an additional loss in $\mathrm{FEV}_{1}$ of $-9 \mathrm{ml} /$ year $(95 \% \mathrm{CI}-13$ to -5 ) compared with the reference group. In contrast, asymptomatic subjects with stage $1 \mathrm{COPD}$ and the reference group had a similar decline in $\mathrm{FEV}_{1}$ $(-3 \mathrm{ml} /$ year $(95 \%$ CI -7 to +1$)$ ]. Moreover, there was a significant difference in the decline in $\mathrm{FEV}_{1}$ decline between asymptomatic and symptomatic subjects within the stage 1 COPD category $(-6 \mathrm{ml} /$ year $(95 \% \mathrm{CI}-11$ to -1$))$. Subjects with stages 2-4 COPD had a consistently greater loss in $\mathrm{FEV}_{1}$ than the reference group.

\section{Respiratory care utilisation}

Unadjusted differences in the report of respiratory care utilisation at SAPALDIA 2 (2002) between the categories are summarised in table 1 . Overall, $10.3 \%$ of individuals with normal lung function at SAPALDIA 1 (1991) reported utilisation of respiratory care during the year preceding the SAPALDIA 2 survey compared with $10.0 \%(p=0.85)$ and $30.8 \%(p<0.01)$ of individuals with stage 1 and stages 2-4 COPD, respectively.

Figure 3 shows the results of the multivariate analysis stratified by GOLD categories and presence of symptoms. Symptomatic subjects with normal lung function were more likely to report respiratory care utilisation (odds ratio (OR) 1.9 (95\% CI 1.6 to 2.3$)$ ). Asymptomatic subjects with stage $1 \mathrm{COPD}$ reported similar rates of respiratory care utilisation to subjects in the reference category (OR 1.05 (95\% CI 0.63 to 1.73)) whereas subjects with symptomatic stage 1 COPD had increased rates (OR 1.62 (95\% CI 1.10 to 2.61)). The strongest predictors for reporting respiratory care utilisation were having COPD stages 2-4 without or with symptoms (OR 4.05 (95\% CI 1.59 to 10.30 ) and 5.67 (95\% CI 2.86 to 11.22 ), respectively). Detailed results are given in table $\mathrm{D}$ in the online supplement.

\section{Quality of life scores}

The unadjusted SF-36 summary scores are shown in table 1. GOLD-defined COPD was associated with lower physical quality of life. In subjects with normal lung function, stage 1 and stages 2-4 COPD, mean (SD) physical component

Table 1 Unadjusted decline in $\mathrm{FEV}_{1}$ over 11 years, respiratory care utilisation and SF-36 summary score at follow-up (SAPALDIA 2 (2002)) stratified by modified GOLD† and symptom categories at SAPALDIA 1 (1991)

\begin{tabular}{|c|c|c|c|c|c|c|c|c|}
\hline & $\begin{array}{l}\text { Mean (SD) FEV } \\
\text { decline }(\mathrm{ml} / \text { year) } \\
(\mathrm{n}=5498)\end{array}$ & p Value§ & $\begin{array}{l}\text { Respiratory care } \\
\text { utilisation } \\
(\%(\mathrm{n})) \\
(\mathrm{n}=\mathbf{6 6 7 0})\end{array}$ & p Value & $\begin{array}{l}\text { Mean (SD) PCS } \\
(n=5000)\end{array}$ & p Value§ & $\begin{array}{l}\text { Mean (SD) MCS } \\
(n=5000)\end{array}$ & p Value§ \\
\hline \multicolumn{9}{|c|}{ Normal lung function $†$} \\
\hline No symptom & $-34(29)$ & & $7.3(265 / 3626)$ & & $53.1(6.7)$ & & $51.5(7.7)$ & \\
\hline With symptom* & $-37(30)$ & $<0.01$ & $14.7(358 / 2434)$ & $<0.01$ & $50.6(9.1)$ & $<0.01$ & $48.7(9.4)$ & $<0.01$ \\
\hline \multicolumn{9}{|l|}{ Stage 1 COPD $\dagger$} \\
\hline No symptom & $-38(36)$ & 0.08 & $8.1(24 / 295)$ & 0.60 & $51.2(8.2)$ & $<0.01$ & $52.5(7.6)$ & 0.05 \\
\hline With symptom* & $-44(38)$ & $<0.01$ & $12.5(28 / 224)$ & $<0.01$ & $48.7(10.8)$ & $<0.01$ & $48.9(10.1)$ & $<0.01$ \\
\hline \multicolumn{9}{|l|}{ Stage 2-4 COPD $\dagger$} \\
\hline No symptom & $-25(43)$ & 0.33 & $23.4(7 / 30)$ & $<0.01$ & $51.4(4.4)$ & 0.09 & $53.9(6.3)$ & 0.08 \\
\hline With symptom* & $-29(39)$ & 0.38 & $34.4(21 / 61)$ & $<0.01$ & $44.2(12.1)$ & $<0.01$ & $50.5(9.8)$ & 0.54 \\
\hline
\end{tabular}

* Report of chronic cough or phlegm or shortness of breath while walking (see online supplement for detailed questions).

$\uparrow$ Prebronchodilator spirometry.

$\$ \chi^{2}$ test for comparison with reference category ("normal lung function, no symptom").

$\S t$ test for unequal variances for comparison with reference category ("normal lung function, no symptom").

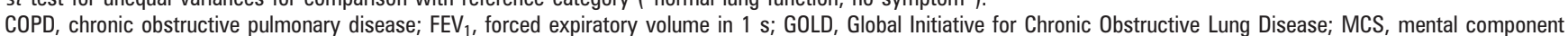
summary of SF-36; PCS, physical component summary of SF-36. 


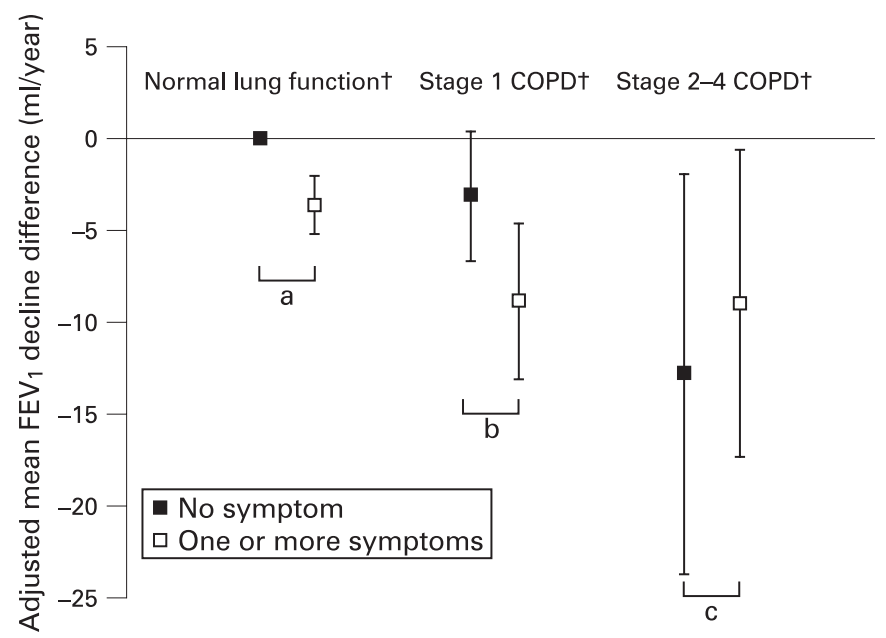

Figure 2 Adjusted difference* in decline in forced expiratory volume in $1 \mathrm{~s}\left(\mathrm{FEV}_{1} ; \mathrm{ml} /\right.$ year with $95 \%$ confidence interval) over 11 years stratified by modified GOLD $\uparrow$ and symptom + categories at SAPALDIA 1 (1991). ${ }^{*}$ Adjusted for age, age squared, sex, baseline $\mathrm{FEV}_{1}$, smoking status, lifetime smoking (packs/year), baseline body mass index, weight change, education level, nationality and study area (random effect). $\uparrow$ Prebronchodilator spirometry. $\$$ One or more symptoms $=$ report of chronic cough or phlegm or shortness of breath while walking. Normal lung function ( $\mathrm{FEV}_{1} / \mathrm{FVC}$ ratio $\geqslant 0.7, \mathrm{FEV}_{1} \geqslant 80 \%$ predicted), no symptoms (reference category; solid black squares). Stage 1 COPD: $\mathrm{FEV}_{1} / \mathrm{FVC}$ ratio $<0.7, \mathrm{FEV}_{1} \geqslant 80 \%$ predicted. Stages 2-4 COPD: $\mathrm{FEV}_{1} /$ FVC ratio $<0.7, \mathrm{FEV}_{1}<80 \%$ predicted. (a) $\mathrm{p}<0.001$; (b) $\mathrm{p}=0.031$; (c) $\mathrm{p}=0.576$.

summary (PCS) scores were 52 (8), 50 (9) and 47 (11), respectively $(p<0.01)$. Mental component summary (MCS) scores did not differ between the three above-mentioned categories (mean (SD) 50 (9); $p=0.17$ ).

After controlling for covariates, only those with symptoms at baseline had significantly lower PCS scores compared with asymptomatic subjects with normal lung function, irrespective of the modified GOLD classification status (fig 4). Compared with the reference category, the PCS scores were lower for symptomatic subjects with stages $2-4$ COPD ( -5.2 points), for those with symptomatic stage 1 COPD ( -1.6 points) and for symptomatic individuals with normal lung function (-1.6 points). In contrast, those who were free of symptoms at baseline reported quality of life scores close to the reference category. In parallel with lung function decline and respiratory care utilisation, there were differences in PCS and MCS scores between asymptomatic and symptomatic subjects with stage 1 COPD (PCS: difference -1.4 (95\% CI -3.0 to +0.2$)$; MCS: difference $-3.2(95 \% \mathrm{CI}-4.9$ to -1.4$))$.

\section{Sensitivity analyses}

In the weighted data analysis the associations between $\mathrm{FEV}_{1}$ decline, respiratory care utilisation, SF-36 summary scores and GOLD and symptom categories were robust and unchanged.

When subjects with physician-diagnosed asthma were included in the analysis, estimates of $\mathrm{FEV}_{1}$ decline for GOLD and symptom categories were close to those using the original cohort. Moreover, in this analysis the difference in $\mathrm{FEV}_{1}$ decline between asymptomatic and symptomatic subjects with stage 1 COPD was larger $(-8 \mathrm{ml} /$ year $(95 \% \mathrm{CI}-13$ to -3$))$ than in the analysis excluding patients with asthma (see table $\mathrm{E}$ in online supplement). The analysis centred on emergency room visits/hospitalisations for respiratory problems, as a specific

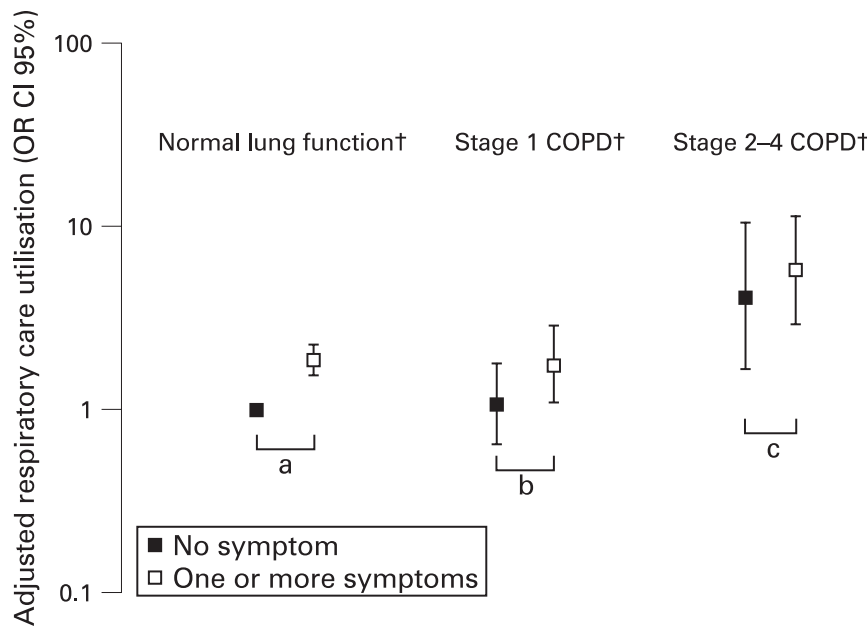

Figure 3 Adjusted ${ }^{*}$ odds ratio of respiratory care utilisation (with 95\% confidence interval) at SAPALDIA 2 (2002) stratified by GOLD† and symptom: categories at SAPALDIA 1 (1991). *Adjusted for age, age squared, sex, baseline forced expiratory volume in $1 \mathrm{~s}\left(\mathrm{FEV}_{1}\right)$, smoking status, lifetime smoking (pack/yr), baseline body mass index, weight change, education level, nationality and study area (random effect). $\dagger$ Prebronchodilator spirometry. $\$$ One or more symptoms = report of chronic cough or phlegm or shortness of breath while walking. Normal lung function ( $\mathrm{FEV}_{1} / \mathrm{FVC}$ ratio $\geqslant 0.7, \mathrm{FEV}_{1} \geqslant 80 \%$ predicted), no symptoms (reference category; solid black squares). Stage 1 COPD: $\mathrm{FEV}_{1} / \mathrm{FVC}$ ratio $<0.7, \mathrm{FEV}_{1} \geqslant 80 \%$ predicted. Stages $2-4$ COPD: $\mathrm{FEV}_{1} /$ FVC ratio $<0.7, \mathrm{FEV}_{1}<80 \%$ predicted. (a) $\mathrm{p}<0.001$; (b) $\mathrm{p}=0.179$; (c) $\mathrm{p}=0.543$.

respiratory care utilisation outcome showed that asymptomatic subjects with stage 1 COPD had a similar rate of events to asymptomatic subjects with normal lung function (OR 0.83 ( $95 \%$ CI 0.19 to 3.71$)$ ) (see table $\mathrm{F}$ in online supplement). As expected, smoking persistence was associated with a faster decline in $\mathrm{FEV}_{1}$ in subjects with stage 1 COPD than in persistent smokers with normal lung function. However, within persistent smokers with stage $1 \mathrm{COPD}$, the decline in $\mathrm{FEV}_{1}$ was not significantly faster for symptomatic subjects than for asymptomatic subjects (data not shown). Subjects with stage 1 COPD who quit smoking had similar long-term outcomes to those with normal lung function who quit smoking. Finally, the interaction between the amount of smoking (pack years between SAPALDIA 1 and 2) and GOLD symptom categories added to the multivariate models for asymptomatic and symptomatic mild COPD subjects was not significant for decline in $\mathrm{FEV}_{1}(p=0.52)$, quality of life (PCS, $p=0.23$; MCS, $p=0.68)$ and respiratory care use $(p=0.19)$.

\section{DISCUSSION}

In this population-based cohort we found that the presence or absence of respiratory symptoms at baseline in adults with stage 1 COPD significantly modified long-term $\mathrm{FEV}_{1}$ decline, respiratory care utilisation patterns and health-related quality of life scores. Symptomatic subjects with stage 1 COPD had longterm faster decline in lung function, increased respiratory care utilisation and lower health-related quality of life than asymptomatic subjects with normal lung function, whereas asymptomatic subjects with stage 1 COPD were similar to the reference group regarding these outcomes. In contrast, subjects with stages 2-4 COPD had worse long-term outcomes, independent of the presence or absence of symptoms at baseline. 


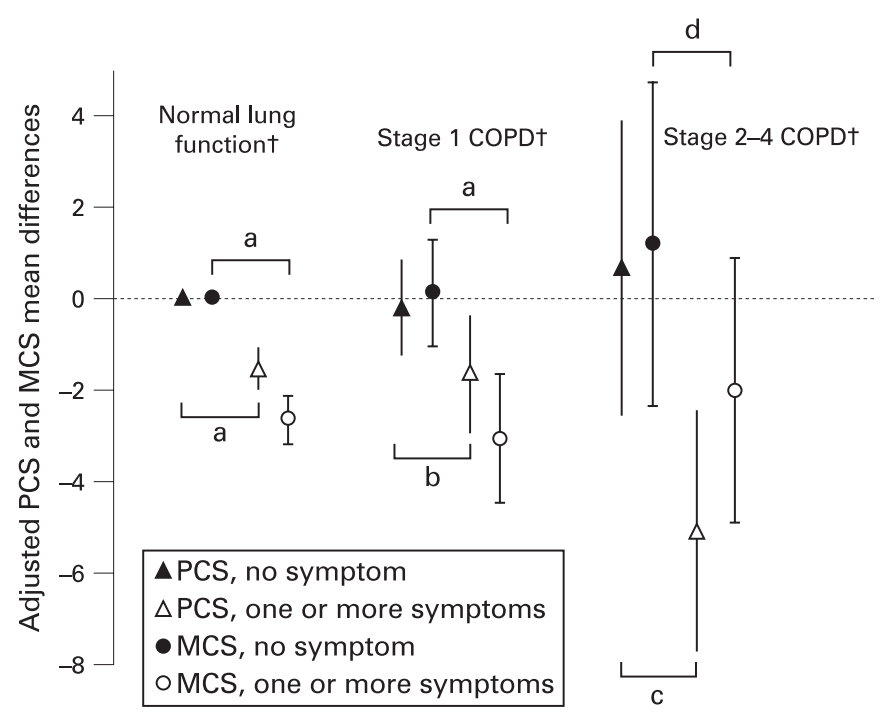

Figure 4 SF-36 summary scores adjusted differences* (with 95\% confidence interval) at SAPALDIA 2 (2002) stratified by GOLD $\dagger$ and symptom $\%$ categories at SAPALDIA 1 (1991). *Adjusted for age, age squared, sex, baseline forced expiratory volume in $1 \mathrm{~s}\left(\mathrm{FEV}_{1}\right)$, smoking status, lifetime smoking (packs/year), baseline body mass index, weight change, education level, nationality and study area (random

effect). $†$ Prebronchodilator spirometry. $\ddagger$ One or more symptoms $=$ report of chronic cough or phlegm or shortness of breath while walking. Normal lung function ( $\mathrm{FEV}_{1} / \mathrm{FVC}$ ratio $\geqslant 0.7, \mathrm{FEV}_{1} \geqslant 80 \%$ predicted), no symptoms (reference category; solid black squares). Stage 1 COPD: $\mathrm{FEV}_{1} / \mathrm{FVC}$ ratio $<0.7, \mathrm{FEV}_{1} \geqslant 80 \%$ predicted. Stages $2-4$ COPD: FEV $/$ FVC ratio $<0.7, \mathrm{FEV}_{1}<80 \%$ predicted. (a) $\mathrm{p}<0.001$; (b) $\mathrm{p}=0.083$; (c) $p=0.005$; (d) $p=0.159$. MCS, Mental Component Summary of the Short-Form General Health Survey (SF-36); PCS, Physical Component Summary of the SF-36.

\section{Decline in lung function}

Historically, accelerated decline in lung function has been recognised as a hallmark of COPD. ${ }^{24}$ In the present study the net $\mathrm{FEV}_{1}$ decline in subjects with stage 1 COPD, taken together, was faster than in subjects with normal lung function. However, we found that the decline in $\mathrm{FEV}_{1}$ within the subjects with stage 1 COPD was statistically different in relation to the absence or presence of respiratory symptoms. Those with stage $1 \mathrm{COPD}$ and symptoms had a significantly faster decline in $\mathrm{FEV}_{1}$ than asymptomatic subjects with normal spirometry. On the other hand, asymptomatic subjects labelled as stage $1 \mathrm{COPD}$ had a trend towards a faster decline in $\mathrm{FEV}_{1}$ which was not statistically significant. Symptoms might be linked to a remodelling process of higher intensity in the airways and, as a consequence, may represent a prognostic marker of functional impairment. ${ }^{25}$ This hypothesis is consistent with the observation that chronic bronchitis without obstruction is a risk factor for developing COPD. ${ }^{26}{ }^{27}$ For example, Lindberg et $a^{26}$ reported a 2 -3-fold increase in the cumulative 10-year incidence of COPD in the presence of respiratory symptoms. This was also found by de Marco et al ${ }^{27}$ in a longitudinal population study where the risk of COPD was higher for those with persistent bronchitis symptoms than in asymptomatic subjects (relative risk 2.9 (95\% CI 1.4 to 5.8 )). However, to our knowledge, this is the first report to show that respiratory symptoms - as defined by chronic cough, phlegm or shortness of breath on walking-predict accelerated lung function decline and other clinically relevant outcomes in subjects with stage 1 COPD.

\section{Respiratory care utilisation}

Symptomatic individuals with stage $1 \mathrm{COPD}$ at SAPALDIA 1 were 1.6 times more likely to report respiratory care utilisation, whereas those free of respiratory symptoms had similar rates to asymptomatic subjects with normal lung function. In the sensitivity analysis the results were unchanged when respiratory care utilisation was strictly defined by emergency room visit or hospitalisation for respiratory problems. The odds ratio of respiratory care utilisation was also increased for symptomatic subjects with normal lung function. To date, no other population study has specifically reported long-term utilisation of respiratory care in subjects with stage 1 COPD. The similar rate of respiratory care utilisation for subjects with asymptomatic stage 1 COPD and those with normal lung function could be interpreted in several ways. Individuals labelled as stage 1 COPD may represent a normal variant of lung function with little potential for developing clinical disease. Another interpretation could be that a larger cohort or a longer follow-up period than 11 years may have more power to observe differences in respiratory care utilisation.

Individuals with stages 2-4 COPD at baseline had up to a sixfold higher risk of respiratory care utilisation later. This is in line with the published literature. A case-control study showed that utilisation of respiratory care was 12 times higher for those with physician-diagnosed COPD than for controls. ${ }^{28}$ Similarly, a population study reported a 5-15-fold higher risk of hospitalisation for subjects with stages 2-4 COPD. ${ }^{29}$ In another cohort of patients with severe to very severe COPD, lower lung function and quality of life were independent predictors of hospitalisations or emergency department visits. ${ }^{30}$

\section{Quality of life}

In parallel with respiratory care utilisation, asymptomatic subjects with stage 1 COPD and those with normal lung function had similar quality of life scores. These results are in line with a study by Antonelli-Incalzi et al who found that stage 1 COPD did not correspond to a meaningful alteration in quality of life. ${ }^{31}$ This study also suggested that the deterioration in the health status was possibly due to respiratory symptoms, which is also indicated by our results. Overall, symptomatic subjects with normal lung function, stage 1 or stages 2-4 COPD had significantly lower physical and mental health scores in the present cohort.

Quality of life in COPD has been mainly assessed in patients recruited from primary care clinics. ${ }^{12} 32$ Compared with these studies, the physical and mental health scores of our subjects were higher, even for those with stages 2-4 COPD. This is not unexpected as our subjects were sampled from the general population and were not primarily identified as patients.

\section{Strengths and limitations}

The strengths of our study are the size of the cohort, which is a representative sample of the Swiss population. For example, the SAPALDIA sample is comparable with other population studies in Europe and with the Swiss population in terms of BMI and smoking behaviour, thus supporting external validity. ${ }^{33}$ The participation rate at follow-up was high. We were able to use detailed information on confounding factors such as lifetime smoking, nationality and education. Nevertheless, some residual confounding related to sociodemographic variables may still be present. Another strength of the study is the rigorous quality control of the spirometric records. ${ }^{16-18}$ 
The limitations of the study are related to the absence of post-bronchodilator spirometric results and repeated lung function measures which may result in overdiagnosis of mild COPD. The potential of misclassification was recently evaluated at $27 \%$ by Johannessen et al in a population study in Norway using bronchodilation and was higher for younger subjects and never-smokers. ${ }^{34} \mathrm{~A}$ Korean study reported a higher misclassification risk of $52 \%{ }^{6}$ However, the effect of this potential misclassification is in part reduced in our study because, unlike the studies in Norway or Korea, we excluded patients with asthma. In addition, our subjects with modified stage 1 COPD were on average older than the reference group and were less likely to be never smokers. Another limitation may be the differential loss to follow-up. As in other cohort studies, subjects with a lower education level and worse lung function were more likely to be non-participants at follow-up. ${ }^{35}$ Such a bias would actually decrease the differences between the GOLD and symptom categories compared with the reference group. It should also be noted that, in our cohort, loss to followup in the stage 1 COPD category was similar to loss to followup in the reference group. In addition, the weighted sensitivity analyses showed that our results were only marginally affected by missing data.

Finally, we noted that the subgroup of subjects with stage 1 COPD who were persistent smokers between both surveys had an accelerated decline in $\mathrm{FEV}_{1}$ with no significant difference between symptomatic and asymptomatic individuals. The presence or absence of symptoms might not therefore be such a strong determinant of $\mathrm{FEV}_{1}$ decline in persistent smokers as it is in other subjects. However, a lack of power in these subgroup analyses requires caution. As a whole, our results indicate that different biological mechanisms may interact in symptomatic and asymptomatic subjects with mild COPD.

In summary, our results show that, in a population-based study, symptomatic and asymptomatic adults with stage 1 COPD have different long-term decline in $\mathrm{FEV}_{1}$, respiratory care utilisation and quality of life scores. In addition, respiratory symptoms at baseline in subjects without GOLD-defined COPD are predictors of these outcomes. This suggests that population cross-sectional studies that are based only on spirometry may misestimate the prevalence of clinically relevant COPD. The risk of COPD misclassification is probably increased by the absence of bronchodilation to define airways obstruction. The heterogeneity of subjects with spirometry-defined stage 1 COPD should be addressed in future population studies in order to predict their long-term clinical outcomes and to estimate the public health needs related to COPD.

Acknowledgements: The authors thank the study participants, the technical and administrative support at the coordinating centres and the medical teams and field workers at the local study sites.

Funding: The Swiss National Science Foundation (grants no 4026-28099, 3347CO108796, 3247B0-104283, 3247B0-104288, 3247B0-104284, 32-65896.01, 3259302.99, 32-52720.97, 32-4253.94), the Federal Office for Forest, Environment and Landscape, the Federal Office of Public Health, the Federal Office of Roads and Transport, the canton's government of Aargau, Basel-Stadt, Basel-Land, Geneva, Luzern, Ticino, Zurich, the Swiss Lung League, the canton's Lung League of Basel Stadt/Basel Landschaft, Geneva, Ticino and Zurich.

Competing interests: None.

Ethics approval: Ethics committee approval was obtained from the participating centres and from the Swiss Academy of Medical Science.

SAPALDIA Team (Swiss cohort study on Air Pollution and Lung Disease in Adults) Study directorate: T Rochat, U Ackermann-Liebrich, JM Gaspoz, P Leuenberger, LJS Liu, NM Probst Hensch, C Schindler. Scientific team: JC Barthélémy, W Berger, R
Bettschart, A Bircher, 0 Brändli, M Brutsche, L Burdet, M Frey, MW Gerbase, D Gold, W Karrer, R Keller, B Knöpfli, N Künzli, U Neu, L Nicod, M Pons, E Russi, P SchmidGrendelmeyer, J Schwartz, P Straehl, JM Tschopp, A von Eckardstein, JP Zellweger, E Zemp Stutz. Scientific collaborators at coordinating centers: P-0 Bridevaux, I Curjuric, D Felber Dietrich, A Gemperli, M Imboden, D Keidel, P Städele-Kessler.

\section{REFERENCES}

1. Global Initiative for Chronic Obstructive Lung Disease (GOLD). Global strategy for the diagnosis, management, and prevention of COPD. 2006. http://goldcopd.com.

2. Lange $\mathbf{P}$, Groth $\mathrm{S}$, Nyboe J, et al. Chronic obstructive lung disease in Copenhagen: cross-sectional epidemiological aspects. J Intern Med 1989;226:25-32.

3. Pena VS, Miravitlles M, Gabriel R, et al. Geographic variations in prevalence and underdiagnosis of COPD: results of the IBERPOC multicentre epidemiological study. Chest 2000;118:981-9.

4. Viegi G, Pedreschi M, Pistelli F, et al. Prevalence of airways obstruction in a general population: European Respiratory Society vs American Thoracic Society definition. Chest 2000;117:339-45S.

5. Mannino DM, Gagnon RC, Petty TL, et al. Obstructive lung disease and low lung function in adults in the United States: data from the National Health and Nutrition Examination Survey, 1988-1994. Arch Intern Med 2000;160:1683-9.

6. Kim SJ, Suk MH, Choi HM, et al. The local prevalence of COPD by postbronchodilator GOLD criteria in Korea. Int J Tuberc Lung Dis 2006;10:1393-8.

7. Shirtcliffe $\mathbf{P}$, Weatherall M, Marsh S, et al. COPD prevalence in a random population survey: a matter of definition. Eur Respir J 2007;30:232-9.

8. Buist AS, McBurnie MA, Vollmer WM, et al. International variation in the prevalence of COPD (the BOLD Study): a population-based prevalence study. Lancet 2007; $370: 741-50$

9. Menezes AM, Perez-Padilla R, Jardim JR, et al. Chronic obstructive pulmonary disease in five Latin American cities (the PLATINO study): a prevalence study. Lancet 2005;366:1875-81.

10. Halbert RJ, Natoli JL, Gano A, et al. Global burden of COPD: systematic review and meta-analysis. Eur Respir J 2006;28:523-32.

11. Mannino DM, Buist AS, Petty TL, et al. Lung function and mortality in the United States: data from the First National Health and Nutrition Examination Survey follow up study. Thorax 2003;58:388-93.

12. Carrasco Garrido P, de Miguel Diez J, Rejas Gutierrez J, et al. Negative impact of chronic obstructive pulmonary disease on the health-related quality of life of patients. Results of the EPIDEPOC study. Health Qual Life Outcomes 2006;4:31.

13. Mannino DM, Doherty DE, Buist SA. Global Initiative on Obstructive Lung Disease (GOLD) classification of lung disease and mortality: findings from the Atherosclerosis Risk in Communities (ARIC) study. Respir Med 2006;100:115-22.

14. Ekberg-Aronsson M, Pehrsson K, Nilsson JA, et al. Mortality in GOLD stages of COPD and its dependence on symptoms of chronic bronchitis. Respir Res 2005;6:98

15. Mannino DM, Buist AS, Vollmer WM. Chronic obstructive pulmonary disease in the older adult: what defines abnormal lung function? Thorax 2007;62:237-41.

16. Martin BW, Ackermann-Liebrich U, Leuenberger $P$, et al. SAPALDIA: methods and participation in the cross-sectional part of the Swiss Study on Air Pollution and Lung Diseases in Adults. Soz Praventivmed 1997;42:67-84.

17. Ackermann-Liebrich U, Kuna-Dibbert B, Probst-Hensch NM, et al. Follow-up of the Swiss Cohort Study on Air Pollution and Lung Diseases in Adults (SAPALDIA 2) 1991 2003: methods and characterization of participants. Soz Praventivmed 2005;50:245-63

18. Kunzli N, Kuna-Dibbert B, Keidel D, et al. Longitudinal validity of spirometers: a challenge in longitudinal studies. Swiss Med Wkly 2005;135:503-8.

19. Quanjer PH, Tammeling GJ, Cotes JE, et al. Lung volumes and forced ventilatory flows. Report Working Party Standardization of Lung Function Tests, European Community for Steel and Coal. Official Statement of the European Respiratory Society. Eur Respir J Supp/ 1993;16:5-40.

20. Bullinger M. German translation and psychometric testing of the SF-36 Health Survey: preliminary results from the IOOLA Project. International quality of life assessment. Soc Sci Med 1995;41:1359-66.

21. Leplege A, Ecosse E, Verdier A, et al. The French SF-36 Health Survey: translation, cultural adaptation and preliminary psychometric evaluation. J Clin Epidemiol 1998;51:1013-23.

22. Apolone G, Mosconi P. The Italian SF-36 Health Survey: translation, validation and norming. J Clin Epidemiol 1998:51:1025-36.

23. Ware JE, Kosinski M. SF-36 Physical and Mental Health Summary Scales: a manual for users of version 1. 2nd ed. Lincoln, Rl: QualityMetric, 2001.

24. Fletcher CM, Peto R, Tinker CM, et al. The natural history of chronic bronchitis and emphysema. Oxford: Oxford University Press, 1976.

25. James $\mathbf{A L}$, Wenzel $\mathrm{S}$. Clinical relevance of airway remodelling in airway diseases. Eur Respir J 2007;30:134-55.

26. Lindberg A, Jonsson AC, Ronmark E, et al. Ten-year cumulative incidence of COPD and risk factors for incident disease in a symptomatic cohort. Chest 2005;127:1544-52

27. de Marco R, Accordini S, Cerveri I, et al. Incidence of chronic obstructive pulmonary disease in a cohort of young adults according to the presence of chronic cough and phlegm. Am J Respir Crit Care Med 2007;175:32-9.

28. Mapel DW, Hurley JS, Frost FJ, et al. Health care utilization in chronic obstructive pulmonary disease. A case-control study in a health maintenance organization. Arch Intern Med 2000;160:2653-8.

29. Mannino DM, Davis KJ. Lung function decline and outcomes in an elderly population. Thorax 2006;61:472-7. 
30. Fan VS, Ramsey SD, Make BJ, et al. Physiologic variables and functional status independently predict COPD hospitalizations and emergency department visits in patients with severe COPD. COPD 2007:4:29-39.

31. Antonelli-Incalzi R, Imperiale C, Bellia V, et al. Do GOLD stages of COPD severity really correspond to differences in health status? Eur Respir J 2003;22:444-9.

32. Fan VS, Curtis JR, Tu SP, et al. Using quality of life to predict hospitalization and mortality in patients with obstructive lung diseases. Chest 2002;122:429-36.
33. Schilling J, Lee CY, Faisst K, et al. Methods of the National Check Bus Project. Soz Praventivmed 2001;46:195-206.

34. Johannessen A, Omenaas ER, Bakke PS, et al. Implications of reversibility testing on prevalence and risk factors for chronic obstructive pulmonary disease: a community study. Thorax 2005;60:842-7.

35. Mannino DM, Reichert MM, Davis KJ. Lung function decline and outcomes in an adult population. Am J Respir Crit Care Med 2006;173:985-90.

\section{Lung alert}

\section{Airway epithelial gene expression to detect lung cancer in smokers}

The sensitivity of bronchoscopy for detecting lung cancer ranges from $30 \%$ for small peripheral lesions to $80 \%$ for centrally located endobronchial lesions, necessitating further invasive diagnostic tests to try to establish the diagnosis. To address this diagnostic problem, the authors searched for profiles of gene expression in large airway epithelial cells knowing that cigarette smoke creates a field of injury in all airway epithelial cells exposed to it. In this study of 129 smokers with suspected lung cancer, the authors have identified an 80-gene biomarker that distinguishes smokers with and without lung cancer. They extracted RNA from normal large airway epithelial cells of 77 smokers and identified the 40 most frequently upregulated and 40 most frequently downregulated genes. This biomarker was then tested on samples from the remaining 52 smokers and on 35 samples from five different institutions.

The diagnostic sensitivity of bronchoscopy was increased to $94 \%$ by combining the traditional cytopathological testing of specimens with the gene biomarker, with a negative predictive value of $93 \%$ and a positive predictive value of $81 \%$. In 92 out of 129 samples with non-diagnostic bronchoscopy, the gene biomarker had a diagnostic accuracy of $85 \%$, sensitivity $89 \%$ and specificity of $83 \%$. For early stage 1 lung cancer, the gene biomarker had a diagnostic sensitivity of about $90 \%$ compared with about $35 \%$ for routine cytopathological testing. Limitations of the study are that the gene biomarker cannot be used on its own owing to its low positive predictive value of $70 \%$, and it does not contribute to the diagnostic aid of non-smokers who develop cancer.

This study shows that gene expression in normal large airway epithelial cells can be used as a lung cancer biomarker and improve the diagnostic sensitivity of bronchoscopy by supplementing the current cytopathological methods. Where facilities become available for performing such gene biomarker testing, further invasive testing may be avoided. A longitudinal study is warranted to find out if false positives on biomarker testing may represent smokers at higher risk of developing lung cancer.

- Spira A, Beane JE, Shah V, et al. Airway epithelial gene expression in the diagnostic evaluation of smokers with suspect lung cancer Nat Med 2007:13:361-6

\section{A B Nanguzgambo}

Correspondence to: A B Nanguzgambo, Specialist Registrar in Respiratory Medicine, Gwynedd Hospital, Bangor, UK; abnangu3@yahoo.co.uk 